\title{
Methicillin Resistant Staphylococcus aureus Contamination of Hands and Mobile Phones of Health Care Workers in a Health Care Setting: A Silent Threat
}

\author{
Sharma BK $^{1 *}$, Regmi SM ${ }^{1}$, Sharma K², Reddy KR ${ }^{1}$, Adhikari S 1 \\ 'Department of Microbiology, ${ }^{2}$ Department of Radiology, \\ Gandaki Medical College\& Teaching Hospital, Pokhara, Nepal.
}

\section{Keywords \\ Health care workers, Mobile Phones, \\ MRSA, Nosocomial. \\ Corresponding author \\ *Dr. Binita Koirala Sharma, PhD \\ Lecturer, Department of Microbiology \\ Gandaki Medical College \& Teaching Hospital, \\ Pokhara, Nepal \\ Email: binita_keshab@yahoo.com}

\begin{abstract}
Background: The extensive use of mobile phones in the hospital among health care workers (HCWs) can lead to infectious agents being transferred from one patient to another and thus serve as a vehicle in the transmission of nosocomial pathogens.

Objectives: This study aimed to investigate the prevalence of Methicillin Resistant Staphylococcus auerus (MRSA) contamination of mobile phones and hands of HCWs in Gandaki Medical College and Teaching Hospital.

Methods: The present study was hospital and laboratory based crosssectional study, carried out from April, 2017 to December, 2017. A total of 100 mobile phone swab and 100 hand swab samples of HCWs were collected and cultured directly on MacConkey agar, blood agar, and mannitol salt agar after $24 \mathrm{hrs}$ of enrichment. All the isolated organisms including MRSA were identified using standard microbiological techniques and subjected to antibiotic susceptibility testing using disc diffusion technique.
\end{abstract}

Results: Among the Gram positive isolates, frequency distribution from mobile phones showed the highest prevalence of coagulase negative Staphylococci (CONS) (34.69\%), followed by Staphylococcus aureus (20.41\%), Bacillus spp (15.31\%), Micrococci spp (11.23\%), however considerable number of Diptheroides (8.16\%), Enterococci (6.12\%) and Streptococcus pneumoniae (4.08\%). Siimilarly from hand swabs CONS (39.62\%), followed by S. aureus (26.42\%), Bacillus spp (10.38\%), Micrococci (11.32\%), Enterococci (6.60\%) and Diptheroids (5.66\%) were isolated. The frequency of MRSA was $20 \%, 25 \%$ among mobile phones and hands of HCWs respectively. Drugs like Vancomycin, Amikacin, Clindamycin and Gentamycin were found quite effective against $S$. aureus in the present study and would be better options for the management of such infections.

Conclusions: Mobile phones and hands of HCWs were the potential source of nosocomial infections including multidrug-resistant pathogens like methicillin-resistant $S$. aureus. 


\section{INTRODUCTION}

Mobile phones are used in various places like hospital halls, laboratories, outpatient department, operation theatres, and various areas in the hospital that may act as fomites and may facilitate transfer of microbes from one patient to another in hospital settings. ${ }^{1}$ The constant handling of mobile phones by single or multiple users in health care facilities makes it an open breeding place for transmission of microorganisms; especially those associated with the skin due to the moisture and optimum temperature of human body especially the palms. Warmth, ideal temperature conditions and heat generated by mobile phones contribute to harboring bacterial populations on such devices at alarming rates., ${ }^{2,3}$

Despite all the advantages gained from the mobile phones, the health hazard it might pose to its users should not be over looked. Mobile phones are daily in contact with the face, ears, mouth and hands during usage and serve as a ready surface for colonization of pathogenic as well as non pathogenic microorganisms and could act as a fomite for microorganisms that eventually transmit more than just a call. ${ }^{4,5}$ Mobile phones are hardly ever cleaned and are often touched during or after examination of patients and handling of specimens without proper hand washing. ${ }^{1}$ In recent years, some studies have been conducted on the potential role played by hands and the mobile phones belonging to health workers and inpatients in the transmission of important nosocomial pathogens. ${ }^{6,7}$ Moreover, the mobile phones are used routinely all day long and the same phones are used both inside and outside the hospital playing a possible role in spreading infections to the outside Community. ${ }^{8}$

Drug resistant pathogens such as methicillin-resistant Staphylococcus aureus (MRSA) and vancomycin resistant Enterococci (VRE) have been recovered from mobile phones; raising important safety concerns about the use of such devices in health care facilities. ${ }^{9}$ Indeed, the delay in detection and reporting such pathogens may lead to prolonged hospitalization of patients, increased morbidity and mortality as well as increased cost of health care ${ }^{10}$ and hence can be considered an economic burden to society more in context of developing country like Nepal.

Nosocomial infections are increasing as these may be spread through the hands of health-care personnel, use of stethoscopes, and other daily instruments used by healthcare personnel. Considering the potential threats of mobile phones and poor hand hygiene that may exaggerate the rate of nosocomial infections, it is of utmost important of strict hygiene standards to prevent hospital acquired infection in a hospital setting. ${ }^{11,12}$ In addition, there are no guidelines on the use and cleanliness of these mobile phones which makes them an important source of hospital acquired infections among the patients in the hospital.

This study aimed to investigate the prevalence of MRSA contamination of mobile phones and hands among HCWs in Gandaki Medical College and Teaching Hospital and their antibiotic susceptibility pattern.

The data obtained in this study could further be used to build awareness about the health risks associated with extensive use of mobile phones in health care setting and poor hand hygiene not only to the patients, HCWs in the hospital but also to their family members. Hospital infection control committee can formulate a sound and feasible policy with respect to mobile phone usage and practice of hand washing within hospital premises.

\section{MATERIALS AND METHODS}

\section{Study area and duration}

The samples were collected from the mobile phones and hands of Health care workers working at various departments of Gandaki Medical College and Teaching Hospital, Prithivi Chowk, Pokhara, Nepal and these samples were processed in the Microbiology Laboratory of same institution from the beginning of April 2017 till the end of December 2017 after obtaining ethical clearance from Gandaki Medical College and Teaching Hospital's Institutional Review Committee.

\section{Number and type of study sample}

This is a descriptive cross-sectional study. A total of 100 mobile phone swab samples and 100 hand swab samples from doctors, nurses, laboratory technicians and helpers from various wards and departments were included in this study. Verbal consent was taken from each participant prior to specimen collection.

\section{Data collection}

Socio-demographic characteristics of the participants: A self-administrated questionnaire was employed to collect information about the socio-demographic characteristics 
(Age, gender, and profession), use of mobile phones in toilets, habit of disinfecting of mobile phones, use of mobile phones by others at workplace and home, knowledge on presence of pathogenic bacteria on mobile phones and hands, habit of hand washing and their view on applying restrictions on use of mobile phones in hospital.

\section{Collection and processing of samples}

The health care worker's mobile phone swab and hand swab samples were collected by means of sterile cotton swabs moistened in sterile saline water $(0.85 \%)$. The swabs were wiped firmly on the entire surface of the mobile phones and hands. The sterilized cotton buds were rotated onto the overall surface area of the mobile phone by keeping the mobile phone in two fingers. Similarly, sterilized cotton buds were rotated onto the overall surface area of palms of both hands and in between of the fingers. The cotton bud swab after swabbing the mobile phone and hands were kept in the sterile small tube containing Brain Heart Infusion (BHI) broth separately and was immediately transported to the Microbiology Laboratory of Gandaki Medical College and Teaching Hospital (GMCTH) for further processing. Specimens contained in clean, leak proof container without visible sign of contamination and proper labeling were included in this study.

All the swabs were cultured directly on blood agar, MacConkey agar and mannitol salt agar (HiMedia). All cultured plates were incubated aerobically at $37^{\circ} \mathrm{C}$ for 24 hours. The primary isolates were subcultured on nutrient agar (HiMedia). Isolates were identified on the basis of colonial appearance, Gram stain, and conventional biochemical tests. ${ }^{12}$ Antibiotic disc susceptibility testing was done to compare isolates recovered from both mobile phones and HCWs' hands by using Clinical Laboratory Standards Institute guidelines (CLSI, Atlanta, USA). ${ }^{13}$ All Staphylococcus aureus isolates were tested for meticillin resistance using a disc of oxacillin $(10 \mu \mathrm{g})$ and using disc of Cefoxitin $(30 \mu \mathrm{g})$ according to CLSI (2017). ${ }^{14}$

\section{Data Collection and Analysis}

All the data were entered into a computer database using standard format, checked for errors and verified. Data maintained in the computer sheets were organized and analyzed by using GraphPad Prism software for Windows (version 8). Data were presented in appropriate tables, figures by calculating percentage, rate etc. Appropriate statistics were applied wherever applicable and $\mathrm{p} \leq 0.05$ level was used as the cutoff value for statistical significance.

\section{RESULTS}

Among total 100 HCWs included in this study; 33\% $(33 / 100)$ were males while $67 \%(67 / 100)$ were females. Professionally majority of them were doctors $(45 / 100$, $45 \%)$, nurses (37/100,37\%), laboratory technicians $6 \%$ $(6 / 100)$ and helpers $9 \%(9 / 100)$. Among the 45 doctors, $62.22 \%(28 / 45)$ were males and $37.78 \%(17 / 45)$ were females. Among six laboratory technicians, 66.67\% (4/6) were males and $33.33 \%(2 / 6)$ were females. All nurses and helpers included in the study were female. The response given by the participants regarding the use of mobile phones are summarized in Table 1. Accordingly $100 \%, 100 \%, 76 \%$ and $82 \%$ of the participants use mobile phones in the health centre, use same mobile phones at home, use mobile phones in toilet and while attending patients respectively, while $83 \%$ had never disinfected their phones. Sixty six percent respondents didn't wash their hands before attending their patients and 22\% don't think that their phones may carry bacteria. Mobile phones of $82 \%$ and $43 \%$ of the HCWs participated in this study were used by their family members at home and by coworkers at workplace respectively. The 21 (21\%) of the health care workers agree on restrictions about use of mobile phones in hospital.

Table 1:Responses of participants for questions related to the use of mobile phones

\begin{tabular}{lcc}
\hline \multicolumn{1}{c}{ Questions } & YesN (\%) & No N (\%) \\
$\begin{array}{l}\text { Do you use your mobile phone in the health } \\
\text { centre? }\end{array}$ & $100(100 \%)$ & $0(0 \%)$ \\
$\begin{array}{c}\text { Do you use the same mobile phone at home? } \\
\text { Do you use your mobile phone in toilet? }\end{array}$ & $100(100 \%)$ & $0(0 \%)$ \\
$\begin{array}{c}\text { Do you answer phone calls while attending } \\
\text { patients/ or during work? }\end{array}$ & $82(82 \%)$ & $18(18 \%)$ \\
$\begin{array}{c}\text { Have you ever disinfected your mobile phone? } \\
\text { Do you wash your hands before attending } \\
\text { your patients? }\end{array}$ & $17(17 \%)$ & $83(83 \%)$ \\
$\begin{array}{c}\text { Do you think mobile phones can carry } \\
\text { bacteria? }\end{array}$ & $78(52 \%)$ & $66(66 \%)$ \\
$\begin{array}{c}\text { Do your families use your mobile phone at } \\
\text { home? }\end{array}$ & $82(82 \%)$ & $18(82 \%)$ \\
$\begin{array}{c}\text { Do your coworkers use your mobile phone at } \\
\text { hospital? }\end{array}$ & $43(43 \%)$ & $57(57 \%)$ \\
$\begin{array}{c}\text { Do you agree on restrictions about use of } \\
\text { mobile phones in hospital? }\end{array}$ & $21(21 \%)$ & $79(79 \%)$ \\
\hline
\end{tabular}




\section{Distribution pattern of Gram-positive bacteria isolated} from various mobile and hand swabs collected from HCWs

The frequency of positive culture among mobile phone and hand swab samples were 97\% (97/100), 94\% (94/100), respectively and most of them showed polymicrobial growth both on their mobile phones and hand swabs.

Among the 165 isolates from mobile phones, the total numbers of Gram positive bacteria isolated was 59.39\% (98/165). Among these Gram positive isolates, the most prevalent bacteria identified was Coagulase Negative Staphylococci (CONS, 34.69\%), followed by S. aureus (20.41\%), Bacillus spp (15.31\%), Micrococci (11.23\%), Diptheroides (8.16\%), Enterococci (6.12\%), and Streptococcus pneumoniae (4.08\%). Similarly among the total 106 Gram positive isolates isolated in hand swabs the most prevalent bacteria identified were CONS (39.62\%) followed by S. aureus (26.42\%), Micrococci (10.38\%), Bacillus spp (11.32\%), Diptheroids (5.66\%) and Enterococci (6.0\%). No isolates of Streptococcus pneumoniae was isolated from any of hand swab sample (Table 2). The bacillus isolated in this investigation was identified according to their morphology and Gram stain. They were Gram positive bacilli and sporulated.

Table 2:Frequency and distribution pattern of of Gram positive bacteria isolated from various mobile phone and hand swabs collected from HCWs

\begin{tabular}{|c|c|c|c|c|c|c|c|}
\hline \multirow{2}{*}{\multicolumn{2}{|c|}{$\begin{array}{l}\text { Gram positive } \\
\text { bacterial agents } \\
\text { identified }\end{array}$}} & \multicolumn{6}{|c|}{ Study Group } \\
\hline & & Doctors & Nurses & $\begin{array}{l}\text { Lab } \\
\text { Techs. }\end{array}$ & Helpers & Total & Percentage \\
\hline \multirow{2}{*}{ CONS } & Mobile & 16 & 11 & 4 & 3 & 34 & $\begin{array}{c}34.69 \\
(34 / 98)\end{array}$ \\
\hline & Hand & 18 & 12 & 5 & 7 & 42 & $\begin{array}{c}39.62 \\
(42 / 106)\end{array}$ \\
\hline \multirow{2}{*}{$\begin{array}{l}\text { Staphylococcus } \\
\text { aureus }\end{array}$} & Mobile & 8 & 6 & 3 & 3 & 20 & $\begin{array}{c}20.41 \\
(20 / 98)\end{array}$ \\
\hline & Hand & 11 & 7 & 5 & 5 & 28 & $\begin{array}{c}26.42 \\
(28 / 106)\end{array}$ \\
\hline \multirow{2}{*}{ Bacillus spp } & Mobile & 4 & 6 & 2 & 3 & 15 & $\begin{array}{c}15.31 \\
(15 / 98)\end{array}$ \\
\hline & Hand & 3 & 4 & 1 & 3 & 11 & $\begin{array}{c}10.38 \\
(11 / 106)\end{array}$ \\
\hline \multirow{2}{*}{ Micrococci } & Mobile & 4 & 4 & 1 & 2 & 11 & $\begin{array}{c}11.23 \\
(11 / 98)\end{array}$ \\
\hline & Hand & 3 & 4 & 2 & 3 & 12 & $\begin{array}{c}11.32 \\
(12 / 106)\end{array}$ \\
\hline \multirow{2}{*}{ Diptheroids } & Mobile & 3 & 3 & - & 2 & 8 & $8.16(8 / 98)$ \\
\hline & Hand & 2 & 3 & - & 1 & 6 & $5.66(6 / 106)$ \\
\hline \multirow{3}{*}{ Enterococci } & Mobile & 1 & 3 & 2 & - & 6 & $6.12(6 / 98)$ \\
\hline & & & & & & & \\
\hline & Hand & 2 & 3 & 1 & 1 & 7 & $6.60(7 / 106)$ \\
\hline \multirow{2}{*}{$\begin{array}{l}\text { Streptococcus } \\
\text { pneumoniae }\end{array}$} & Mobile & - & 2 & 2 & - & 4 & $4.08(4 / 98)$ \\
\hline & Hand & - & - & - & - & - & - \\
\hline
\end{tabular}

\section{Antibiotic Susceptibility Test of the isolated Gram- positive bacteria from mobile phones}

Various antibiotics were used for antibiotic susceptibility pattern determination using Kirby Bauer disc diffusion method. Coagulase Negative Staphylococci showed 100\% sensitive to Vancomycin, followed by Amikacin (94.12\%), Clindamycin (88.24\%), Gentamycin (85.29\%), Oxacillin (76.47\%), Cefoxitin (76.47), Ciprofloxacin (67.65\%), Amoxicillin+ Clavulanate (52.94\%), Cotrimoxazole (50\%), Chloramphenicol (47.05\%), Erythromycin (41.17\%) and Ampicillin (11.76\%). Isolated all CONS showed 100\% resistant to Penicillin (table 3). Staphylococcus aureus was found to be $100 \%$ resistant to Penicillin. No Vancomycin resistant $S$. aureus was reported. The effective antibiotics were Amikacin (95\%), Clindamycin (90\%), Gentamicin (85\%), Cefoxitin (80\%), Oxacillin (80\%), Chloramphenicol (65), Ciprofloxacin (65\%), Amoxicillin+ Clavulanate (60\%), Cotrimoxazole (45\%) and Erythromycin (25\%) (Table 3).

No vancomycin resistant Enterococci were observed in this study. The isolated Enterococci were sensitive to Amikacin (83.33\%), Gentamicin (83.33\%), Amoxicillin+ Clavulanate (66.66\%), Clindamycin (66.66\%), Chloramphenicol (50\%), Ciprofloxacin (50\%), Cotrimoxazole (33.33\%), Penicillin (33.33\%) and Erythromycin (33.33\%) (table 3). All isolated Enterococci are $100 \%$ resistant to Ampicillin. However, Streptococcus pneumoniae 100\% sensitive to Vancomycin followed by $75 \%$ sensitive to Amikacin, Gentamycin, Clindamycin, Cotrimoxazole, Ciprofloxacin, $50 \%$ sensitive to Chloramphenicol, Amoxicillin + Clavulanate, Penicillin and 25\% sensitive to Erythromycin. (Table 3). 100\% Streptococcus pneumoniae are resistant to Ampicillin.

Table 3: Antibiotic susceptibility pattern of the isolated Gram-positive bacteria from mobile phones

\begin{tabular}{ccccc}
\hline Organisms & $\begin{array}{c}\text { Coagulase Negative } \\
\text { Staphylococci }\end{array}$ & $\begin{array}{c}\text { Staphylococcus } \\
\text { aureus }\end{array}$ & $\begin{array}{c}\text { Enterococcus } \\
\text { spp }\end{array}$ & $\begin{array}{c}\text { Streptococcus } \\
\text { pneumoniae }\end{array}$ \\
\hline Total no. of isolates & $\mathbf{3 4}$ & $\mathbf{2 0}$ & $\mathbf{6}$ & $\mathbf{4}$ \\
\hline \multicolumn{5}{c}{ No. (\%) } \\
of isolates sensitive to & \\
OX & $26(76.47)$ & $16(80)$ & - & - \\
CX & $26(76.47)$ & $16(80)$ & - & - \\
GEN & $29(85.29)$ & $17(85)$ & $5(83.33)$ & $3(75)$ \\
P & $0(0)$ & $0(0)$ & $2(33.33)$ & $2(50)$ \\
AMC & $18(52.94)$ & $12(60)$ & $4(66.66)$ & $2(50)$ \\
CPL & $23(67.65)$ & $13(65)$ & $3(50)$ & $3(75)$ \\
COT & $17(50)$ & $9(45)$ & $2(50)$ & $3(75)$ \\
Cl & $30(88.24)$ & $18(90)$ & $4(66.66)$ & $3(75)$ \\
C & $16(47.05)$ & $13(65)$ & $3(50)$ & $2(50)$ \\
ERY & $14(41.17)$ & $5(25)$ & $2(33.33)$ & $1(25)$ \\
V & $34(100)$ & $20(100)$ & $6(100)$ & $4(100)$ \\
AK & $32(94.12)$ & $19(95)$ & $5(83.33)$ & $3(75)$ \\
AMP & $4(11.76)$ & $0(0)$ & $0(0)$ & $0(0)$ \\
\hline
\end{tabular}


OX, Oxacillin; CX, Cefoxitin; GEN, Gentamycin; P, Penicillin; AMC, Amoxicillin+Clavulanate; CPL, Ciprofloxacin; COT, Cotrimoxzole; $\mathrm{Cl}$, Clindamycin; C, Chloramphenicol; ERY, Erythromycin; V, Vancomycin; AK, Amikacin, AMP, Ampicillin

\section{Antibiotic susceptibility test of the isolated Gram positive bacteria from hand swabs}

Coagulase negative staphylococci showed 100\% sensitive to Vancomycin, followed by amikacin (90.47\%), oxacillin (76.19\%), Cefoxitin (76.19), Ciprofloxacin (69.08\%), Clindamycin (66.66\%), Gentamycin (66.66\%), Chloramphenicol (47.61\%), Cotrimoxazole (45.23\%), Amoxicillin+ Clavulanate (45.23\%), Erythromycin (42.85\%) and ampicillin (26.19\%). All isolated CONS showed $100 \%$ resistant to Penicillin (Table 4).

Staphylococcus aureus was found to be $100 \%$ resistant to penicillin. No vancomycin resistant $S$. aureus was reported. The effective antibiotics were Amikacin (92.85\%), Gentamicin (78.57\%), Clindamycin (75.0\%), Cefoxitin (75\%), Cxacillin (75\%), Ciprofloxacin (53.57\%), Chloramphenicol (46.42\%), Cotrimoxazole (39.28\%), Amoxicillin+ Clavulanate (32.14\%), and Erythromycin (14.28\%) (Table 4).

No vancomycin resistant Enterococci were observed in this study. The isolated Enterococci were sensitive to Amikacin (100.0\%), Gentamicin (84.85\%), Clindamycin (71.42\%), Amoxicillin+ Clavulanate (57.14\%), Chloramphenicol (57.14\%), Erythromycin (57.14\%), Cotrimoxazole (42.85\%), Ciprofloxacin (42.85\%), Ampicillin (42.85\%) and Penicillin (42.85\%\%) (Table 4).

Table 4:Antibiotic susceptibility pattern of the isolated Gram positive bacteria from hand swabs

\begin{tabular}{cccc}
\hline Organisms & $\begin{array}{c}\text { Coagulase Nega- } \\
\text { tive Staphylococci }\end{array}$ & $\begin{array}{c}\text { Staphylococcus } \\
\text { aureus }\end{array}$ & Enterococcus spp \\
\hline Total no. of isolates & 42 & 28 & 7 \\
\hline \multicolumn{4}{c}{ No. (\%) of isolates sensitive to } \\
OX & $32(76.19)$ & $21(75)$ & - \\
CX & $32(76.19)$ & $21(75)$ & - \\
GEN & $28(66.66)$ & $22(78.57)$ & $6(84.85)$ \\
P & $0(0)$ & $0(0)$ & $3(42.85)$ \\
AMC & $19(45.23)$ & $9(32.14)$ & $4(57.14)$ \\
CPL & $29(69.08)$ & $15(53.57)$ & $3(42.85)$ \\
COT & $19(45.23)$ & $1(39.28) 1$ & $3(42.85)$ \\
Cl & $28(66.66)$ & $21(75)$ & $5(71.42)$ \\
C & $20(47.61)$ & $13(46.42)$ & $4(57.14)$ \\
ERY & $18(42.85)$ & $4(14.28)$ & $4(57.14)$ \\
V & $42(100)$ & $28(100)$ & $7(100)$ \\
AK & $38(90.47)$ & $26(92.85)$ & $7(100)$ \\
AMP & $11(26.19)$ & $0(0)$ & $3(42.85)$ \\
\hline
\end{tabular}

OX, Oxacillin; CX, Cefoxitin; GEN, Gentamycin; P, Penicillin; AMC, Amoxicillin+Clavulanate; CPL, Ciprofloxacin; COT, Cotrimoxzole; $\mathrm{Cl}$, Clindamycin; C, Chloramphenicol; ERY, Erythromycin; V, Vancomycin; AK, Amikacin, AMP, Ampicillin

\section{Prevalence of methcillin resistant Staphylococcus aureus (MRSA) among the isolated Staphylococcus aureus from mobile and hand swabs}

Out of total 100 mobile phone swab samples processed and 20 Staphylococcus aureus isolated, 20\% (4/20) were methicillin resistant Staphylococcus aureus (MRSA) and 80\% (16/20) were methicillin sensitive Staphylococcus aureus (MSSA) (Fig 1). Similarly, out of total 100 hand swab samples processed and 28 Staphylococcus aureus isolated, 25\% (7/28) were MRSA and 75\% (21/28) were MSSA (Fig 1). Overall prevalence of MRSA isolated from mobile phones and hand swab samples didn't show any significant difference $(\mathrm{p}=0.4985)$ (Table 5).

Table 5: Prevalence of MRSA among the isolated Staphylococcus aureus from mobile and hand swabs

\begin{tabular}{ccccc}
\hline Data analyzed & $\begin{array}{c}\text { Mobile swabs } \\
\text { (\%) }\end{array}$ & Hand swabs (\%) & Total (\%) & P value \\
MRSA & 20 & 25 & 45 & \\
MSSA & 80 & 75 & 155 & $\mathrm{P}=0.4985$ \\
Total & 100 & 100 & 200 & \\
\hline
\end{tabular}

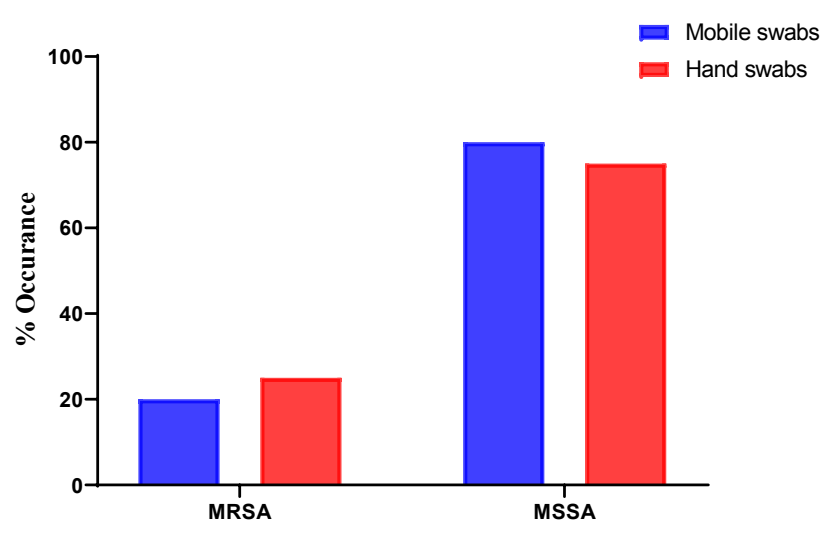

Fig 1:Percentage occurrence of MRSA recovered among the isolated Staphylococcus aureus from mobile phone and hand swabs

\section{DISCUSSION}

MRSA is one of the most important cause of hospital acquired infections with a significant morbidity and 
mortality. ${ }^{15,16}$ In a healthcare setup a patient may acquire MRSA through the hands, clothes, mobile phones and equipment of health care workers. Screening of health care workers mobile phones and hands colonised with MRSA will be helpful in preventing the spread of this organism in a hospital. With this background the present study was undertaken to investigate the prevalence of MRSA contamination of mobile phones and hands of HCWs in Gandaki Medical College and Teaching Hospital and their antibiotic susceptibility pattern.

The frequency of positive culture among mobile phone and hand swabs were 97\% (97/100), 94\% (94/100), respectively and most of them showed polymicrobial growth both on their mobile

phones and hand swabs which were in accordance with the study done by Arora et al, ${ }^{1}$ Ugler et al, ${ }^{17}$ Tambe et $\mathrm{al}^{18}$ who had showed 91.6\%, 94.5\%, 90.98\% of phones of bacterial contamination with different type of bacteria.

This study revealed high level of bacterial contaminants on mobile phones and hands of HCWs which were contaminated with considerable number of Gram positive bacteria. The present study showed that CONS (34.69\%) and S. aureus (20.41\%) were the prevalent organisms for mobile phones and similarly that of CONS 39.62\% and S. aureus $26.42 \%$ for hand swabs of HCWs. This result is in consistent with that reported by Anupriya et $\mathrm{al}^{19}$ Bhumbla et $\mathrm{al}^{20}$ and Ulger et al. ${ }^{17}$

A high percentage of Bacillus spp was isolated from this research and its predominance could be explained by the fact that Bacillus spp are ubiquitous in nature with their spores able to resist environmental changes, withstand dry heat and certain chemical disinfectants for moderate periods.

CONS, S. aureus and Bacillus spp recovered during this study constitute a major part of normal skin flora; which probably explains its high prevalence as a contaminant, as it can easily be discharged by several human activities and they may be passed from person to person by direct contact or via surfaces, including door handles. These organisms are potentially pathogenic and may cause disease due to their high resistance such as food poisoning, boils, abscesses, pimples, wound infections if enter the body can lead to bacteremia and sepsis, pneumonia, meningitis, and osteomyelitis. This observation is in agreement with the findings of other researchers (Brooks et al). ${ }^{21}$

There is an alarming increase of antibiotic resistance in bacteria that cause either community infections or hospital acquired infections. In this study, the resistance of $S$. aureus was found to be $100 \%$ resistant to Penicillin which is in accordance to Radhakrishnan et al. ${ }^{22}$ Though Araliet $\mathrm{al}^{23}$ observed $4.9 \%$ resistance was for Vancomycin among the isolated $S$. aureus from the anterior nares of school going children, no vancomycin resistant $S$. aureus was reported in this study among mobile phones and hand swabs of HCWs which is similar to the findings of Radhakrishnan et al. ${ }^{22}$ The effective antibiotics were Amikacin (95\%), Clindamycin (90\%), Gentamicin (85\%), Cefoxitin (80\%), Oxacillin (80\%), Chloramphenicol (65), Ciprofloxacin (65\%), Amoxicillin+ Clavulanate (60\%), Cotrimoxazole (45\%) and Erythromycin (25\%) for $S$. aureus isolated from mobile phones. Likewise, the effective antibiotics for $S$, aureus isolated from mobile phones were Amikacin (92.85\%), Gentamicin (78.57\%), Clindamycin (75.0\%), Cefoxitin (75.0\%), Oxacillin (75\%), Amoxicillin+ Clavulanate (60.71\%), Ciprofloxacin (53.57\%), Chloramphenicol (46.42), Cotrimoxazole (39.28\%) and Erythromycin (14.28\%). Overall resistance of $S$. aureus to antibiotics likes Ciprofloxacin, Co-trimoxazole and Amoxicillin-Clavulanic acid was found high. These antibiotics being cheaper and easy to administer were extensively used in past few years might be the reasons for their high resstance pattern. Use of expensive and injectable antibiotics like Amikacin was less in small clinics and reflects on higher percentage of sensitive isolates.

The prevalence of MRSA among the isolated $S$. aureus in this study among the samples from mobile phones was $20 \%(4 / 20)$ and 25\% (7/28) from hand swabs which was comparable with earlier reports of MRSA from Nepal which reported prevalence of $15.4 \%$ to $29 \%$ by Kumari et $\mathrm{al}^{24}$ and Subedi and Brahmadathan. ${ }^{25}$

Although, the presence of MRSA among health care workers mobile phones and hand swabs in this hospital is not alarming, it is important to emphasize the need for stringent hospital infection control policies. Since HCWs may act as silent carriers of MRSA and play a vital role in spreading nosocomial infection including MRSA in community and family members, it is also important to stress the importance of hand hygiene among health care workers to prevent transmission of MRSA within the hospital and also to their family members. However, further research is necessary to determine 
the quantitative association between increased hand hygiene compliance and reduction in MRSA. Moreover, hospital infection control committee shall be established to monitor the practice of hand washing techniques and assessing the outcomes at frequent intervals to reduce the MRSA prevalence amongst HCWs.

\section{CONCLUSION}

Mobile phones and hands of HCWs were the potential source of nosocomial infections including multidrugresistant pathogens like methicillin-resistant $S$. aureus. Appropriate hand hygiene is the most important measure that should be practiced during patient care to reduce the spread of MRSA and nosocomial infections. Thus strict hand hygiene, decontamination of mobile phones and restriction of the use of mobile phones in high risk areas should be advocated to prevent the spread of infection in the hospital settings.

\section{Acknowledgments}

The authors would like to express deep thanks and sincere appreciation to Dr Madhu Timilsina, intern, Gandaki Medical College for her help during sample collection. Authors would like to thank to the laboratory technologist Mr. Bashanta Bhujel and all the faculty members of department of Microbiology, Gandaki Medical College and Teaching Hospital for their support.

\section{REFERENCES}

1. Arora U, Devi P, Chadha A, Malhotra S. Cell phones a modern stay house for bacterial pathogens. J K Sci. 2009;11(3):127-9.

2. Jaya Madhuri R, Saraswathi, M, Mahitha G, Bhargavi M, Deepika S. Bacterial contamination of mobile phones and computers in microbiological laboratories. Eur J Biotechnol Biosci. 2015;3(9):51-5.

3. Tagoe DN, Gyande VK, Ansah EO. Bacterial contamination of mobile phones: When your mobile phone could transmit more than just a call. Web Med Central Microbiol.2011;2(10): WMC002294.
4. Singh A, Purohit B. Mobile phones in hospital settings: A seriousthreat to infection. Occup Health Saf. 2012;81(3):42-4.

5. Bhat SS, Hegde SK, Salian S. Potential of mobile phones to serve as a reservoir in spread of nosocomial pathogens. Online J Health Allied Scs. 2011;10(2):14.

6. Cockerill FR, Wikler MA, Bush K, Dudley MN, Eliopoulos GM, Hardy DJ et al. Performance standards for antimicrobial susceptibility testing: Twenty-first informational supplement. CLSI.2011;31.

7. Pal S, Juyal D, Adekhandi S, Sharma M, Prakash R, Sharma N, et al. Mobile phones: Reservoirs for the transmission of nosocomial pathogens. Adv Biomed Res. 2015;4:144.

8. Karabay O, Koçoglu E, Tahtaci M. The role of mobile phones in the spread of bacteria associated with nosocomial infections. J Infect Developing Countries.2007; 1(1):72-3.

9. Mark D, Leonard C, Breen H, Graydon R, O'Gorman C, Kirk S. Mobile phones in clinical practice: Reducing the risk of bacterial contamination. GMS Hygiene and Infection Control.2015;10: ISSN2196-5226.

10. Lautenbach E, Patel JB, Bilker WB, Edelstein PH, Fishman NO. Extended-Spectrum $\beta$-lactamaseproducing E. coli and Klebsiella pneumoniae: Risk factors for infection and impact of resistance on outcomes. Clinical Infectious Diseases. 2001;32:1162-72.

11. Razine R, Azzouzi A, Barkat A, Khoudri I, Hassouni F, Chefchaouni AC et al. Prevalence of hospital-acquired infections in the University Medical Center of Rabat, Morocco. Int Arch Med. 2012;5(1):26.

12. Colle G, Fraser AG, Marmion BP, Simmons A. Mackie and McCartney practical microbiology, Churchill Livingeston, 14 Edn. 1996. New York, USA.

13. National committee for clinical laboratory standards performance standards for 
antimicrobial disk susceptibility tests approved standard 2000; Villanova, PA: NCCLS.

14. Pa W. Clinical and Laboratory Standards Institute, Performance standards for antimicrobial susceptibility testing, twentysecond informationalsupplement, CLSI, Document M100 -S27. USA: CLSI; 2017.

15. Boucher H, Miller LG, Razonable RR. Serious infections caused by methicillin-resistant Staphylococcus aureus. Clin Infect Dis. 2010;51 (Suppl 2):S183-97.

16. McNicoll L, Marsella M. The growing problem of methicillin-resistant Staphylococcus aureus: Will hospitals prevail? Med Health. 2010;93:267-70.

17. Ulger F, Esen S, Dilek A, Yanik K, Gunaydin M, Leblebicioglu H. Are we aware how contaminated our mobile phones with nosocomial pathogens? AnnClin Microbiol Antimicrob. 2009;8(1):7.

18. Tambe NN, Pai C. A study of microbial flora and MRSA harbored by mobile phones of health care personnel. Int J Rec Tre Sci Tech. 2012;4:14-8.

19. Anupriya A, Puhalenthi K, Jeya Keerthi S, Prethi $\mathrm{R}$, Hemasri V. Microbial contamination of mobile phones in a teritary care hospital. Int J Community Med Public Health. 2018; 5:23136.

20. Bhumbla U, Ahmad SM, Mathur DR, Bandey L, Mathur G. Study on microbial contamination of mobile phones and their role in nosocomial infections in a tertiary hospital of south India. Asian J Pharm Clin Res. 2016;9(3):201-2.

21. Brooks GF, Carrol KC, Butel JS, Morse SA, Jawetz MA. Medical Microbiology. 24th edition.2007. McGraw-Hill publishers, New York, USA.

22. Radhakrishna M, Souza MD, Kotigadde
S. Prevalence of methicillin resistant Staphylococcus aureus carriage amongst health care workers of critical care units in Kasturba Medical CollegeHospital, Mangalore, India. J Clin Diagnos Res. 2013;2:697-700.

23. Arali S, Kulkarni V, Manjula GN, Gaddad S, Jayaraj Y, Shivannavar C. Prevalence and antibiotic susceptibility profile of MRSA isolated from the anterior nares of school going children in Gulbarga. Int J Med Sci Public Health. 2016;5(4):620.

24. Kumari N, Mohapatra TM, Singh YI. Prevalence of methicillin-resistant Staphylococcus aureus (MRSA) in a Tertiary-Care Hospital in Eastern Nepal. Journal of Nepal Medical Association. 2008;47:53-6.

25. Subedi S, Brahmadathan KN. Antimicrobial susceptibility patterns of clinical isolates of Staphylococcus aureus in Nepal. European Society of Clinical Microbiology and Infectious Diseases. 2005;11:35-7. 